Check for updates

Cite this: Mater. Adv., 2021, 2, 376

Received 10th July 2020,

Accepted 16th November 2020

DOI: 10.1039/d0ma00497a

rsc.li/materials-advances

\title{
Poly-anthraquinone sulfide isomers as electrode materials for extended operating temperature organic batteries $\dagger$
}

\author{
Benjamin Flamme, Badr Jismy, Mohamed Abarbri (iD and Mérièm Anouti (iD *
}

\begin{abstract}
Three polyanthraquinone sulfide (PAQS) isomers were synthesized, characterized and included in a comparative study of electrochemical performances as organic material cathodes. The performances of the 1,5-PAQS, 2,6-PAQS, and 1,8-PAQS isomers were compared as a function of charge density, longterm stability and operating temperature. The results obtained showed superior performances for polymers that offer the best spatial flexibility, thus allowing the carbonyl groups to be more accessible to $\mathrm{Li}$ cations. The performances (200 $\mathrm{mA} \mathrm{h} \mathrm{g}^{-1}$ at $4 \mathrm{C}$ ) of $\mathbf{1 , 5}$ and $\mathbf{2 , 6 - P A Q S}$ isomers were preserved for up to 1000 cycles. The more flexible 2,6-PAQS isomer demonstrated a remarkable ability to endure fast cycling from $60{ }^{\circ} \mathrm{C}$ to $-30{ }^{\circ} \mathrm{C}$ without a significant decrease in capacity retention (which decreased from $98.1 \%$ to $93.4 \%$ ) thanks to its flexible structure. The reduced effect of the temperature on long term cycling results obtained with 2,6-PAQS allows it to deliver an energy density of $275 \mathrm{~W} \mathrm{~h} \mathrm{~kg}^{-1}$ at $-30{ }^{\circ} \mathrm{C}$. It therefore appears that, thanks to their low cost, environmental benignity and high sustainability, the selected PAQS isomers are promising candidates for alternative electrode materials in full-organic batteries dedicated to low temperature operation.
\end{abstract}

\section{Introduction}

Nowadays, lithium-ion batteries are already widely used in our daily lives and will continue to conquer new sectors, but their development lags behind the global demand for this type of energy storage device. ${ }^{1,2}$ The principal difficulties remain their low power density and their cost, but also the environmental impact linked to their manufacture. ${ }^{3,4}$ The intensive use of transition metal resources such as cobalt and nickel in $\operatorname{LiM}_{x} \mathrm{O}_{y}$ ( $\mathrm{M}=\mathrm{Co}, \mathrm{Ni}, \mathrm{Mn} .$.$) cathode electrodes is spurring the search$ for alternative greener electrode materials. ${ }^{5}$ The attention of many groups has therefore turned to different systems such as redox-flow batteries (RFB), lithium-sulfur (Li-S) or organic batteries (OBs). Organic electrode materials (OEMs) are attracting more attention because of their multiple properties, ${ }^{4,6,7}$ their durability, eco-compatibility, ${ }^{8-11}$ and their ability to operate with multiple alkali ions, such as $\mathrm{Li}^{+},{ }^{12,13} \mathrm{Na}^{+14,15}$ or $\mathrm{K}^{+} .16,17$ OEMs could be used in a wide variety of systems, ${ }^{18}$ i.e. supercapacitors, ${ }^{19}$ aqueous batteries ${ }^{20}$ and hybrid systems. ${ }^{21-23}$

Laboratoire PCM2E, EA 6299, Université de Tours, Faculté des Sciences et Techniques Parc de Grandmont, 37200 Tours, France.

E-mail: meriem.anouti@univ-tours.fr

$\dagger$ Electronic supplementary information (ESI) available. See DOI: 10.1039/ d0ma00497a

\$ Present address: Faculté des Sciences et Techniques, Parc de Grandmont, 37200 Tours, France.
Among the different families of OEMs, ${ }^{6}$ quinones and their derivatives appear to be the most promising type, ${ }^{24,25}$ thanks to their high availability and the good electrochemical reversibility of their redox system. ${ }^{26,27}$ However, the main drawback of quinone derivatives is their solubility in organic solvents that are commonly used in lithium-ion batteries. ${ }^{4}$ Small molecules of benzo-, naphtho- or anthraquinone homologues contaminate the electrolyte and reduce its electrochemical due to slow and continuous dissolution. ${ }^{28}$ One approach involves working with monomers and limiting the dissolution via the formulation as the Chen and $\mathrm{Li}$ groups reported recently. ${ }^{29-31}$ Another approach to avoid dissolution is to polymerize these small units in order to obtain an insoluble polymer. This approach is still currently in use and effective as shown recently by Liang et al. and Wang et al. ${ }^{32,33}$ The macromolecules thus obtained are almost insoluble in most organic solvents, and this was particularly the case for poly-anthraquinone sulfides (PAQS). ${ }^{28,34,35}$ Despite the reduced nominal capacity of PAQS $\left(C^{\text {th }}=225 \mathrm{~mA} \mathrm{~h} \mathrm{~g}^{-1}\right)$ because of the higher molar mass of the anthraquinone monomer, and the introduction of a C-S bond by "Philipp's" polycondensation, ${ }^{36}$ PAQS offer a greater degree of freedom and a wider diversity of spatial arrangement thanks to position isomers. It turns out that these two parameters influence the accessibility to carbonyl moieties and the diffusion of cations and consequently the performances. We report herein the comparative performances of three PAQS position isomers used 

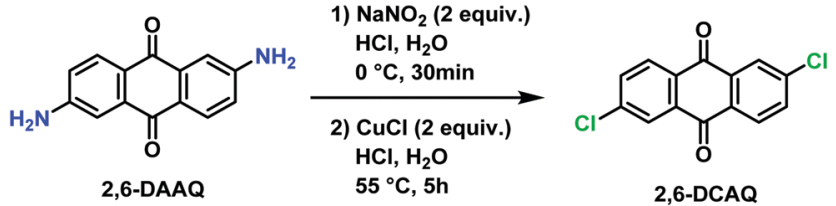

Scheme 1 Synthesis of 2,6-dichloroanthraquinone (2,6-DCAQ).

as OEMs and the position effect on electrochemical performance and stability in a wide temperature range. The objective was to demonstrate that the spatial arrangements of PAQS isomers influence the charge distribution and the carbonyl group accessibility, and how much it impacts the electrochemical performances.

\section{Experimental section}

\section{Materials and synthesis}

2,6-Dichloroanthraquinone (2,6-DCAQ) was prepared based on the procedure reported by Zhang et al. ${ }^{37}$ The reaction was carried out in two steps as described in Scheme 1. First, sodium nitrite $(5.8 \mathrm{~g}, 84 \mathrm{mmol})$ was dissolved in ice-cold water $(20 \mathrm{~mL})$ and added slowly in a $1000 \mathrm{~mL}$ flask containing a solution of 2,6-diaminoanthraquinone (10 g, $42 \mathrm{mmol})$ and $\mathrm{HCl}(37 \%$, $60 \mathrm{~mL}$ ). The reaction mixture was maintained at $0{ }^{\circ} \mathrm{C}$ for 30 minutes to form the diazonium intermediate. Then, $\mathrm{CuCl}$ (8.32 $\mathrm{g}, 84 \mathrm{mmol}$ ) was then added slowly and the mixture was heated at $55{ }^{\circ} \mathrm{C}$ for 5 hours. The progress of the reaction was monitored by TLC (PE/EtOAc, 9/1).

After completion of the reaction, the mixture was filtered, and the obtained solid was washed several times with $\mathrm{HCl}$ $(37 \%, 3 \times 20 \mathrm{~mL})$ and $\mathrm{H}_{2} \mathrm{O}(3 \times 200 \mathrm{~mL})$ successively, and then dried under vacuum at $50{ }^{\circ} \mathrm{C}$. The desired product was obtained after several extractions using $\mathrm{CH}_{2} \mathrm{Cl}_{2}(10 \times 200 \mathrm{~mL})$ followed by removal of the solvent. The crude product was purified by chromatography on silica gel using (PE/EtOAc, 9/1) as an eluent, to afford the pure 2,6-DCAQ as a beige solid in $52 \%$ yield (6.02 g). M.p. $292-294{ }^{\circ} \mathrm{C}$ (Lit. ${ }^{37}$ M.p.: $291{ }^{\circ} \mathrm{C}$, Lit. M.p.: $295-$ $\left.297{ }^{\circ} \mathrm{C}^{38}\right) .{ }^{1} \mathrm{H}$ NMR $\left(300 \mathrm{MHz}, \mathrm{CDCl}_{3}\right) \delta 8.35-8.21(\mathrm{~m}, 4 \mathrm{H}), 7.77$ (dd, $J=8.4,2.1 \mathrm{~Hz}, 2 \mathrm{H}$ ). HRMS (ESI) $m / z[\mathrm{M}+\mathrm{H}]^{+}$calcd for $\mathrm{C}_{14} \mathrm{H}_{7} \mathrm{Cl}_{2} \mathrm{O}_{2}$ : 275.9703; found: 275.9708 .

1,5-PAQS, 1,8-PAQS and 2,6-PAQS were synthesized by polycondensation using the corresponding dichloroanthraquinone (DCAQ) and anhydrous sodium sulfide as reagents according to methods described previously, ${ }^{6,16,28}$ The chemical reaction is shown in Scheme 2. All PAQS were prepared using anhydrous $\mathrm{Na}_{2} \mathrm{~S}$ (1.41 g, $18 \mathrm{mmol}$ ) obtained by removing the hydrated

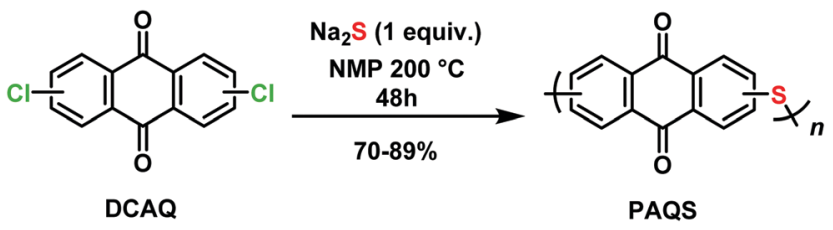

Scheme 2 DCAQ polymerization affording the desired PAQS isomers. water through azeotropic dehydration in toluene $(10 \mathrm{~mL})$ and NMP (40 mL). After evaporating toluene from the mixture, a stoichiometric quantity of corresponding DCAQ ( $5 \mathrm{~g}, 18 \mathrm{mmol})$ was added and the mixture was heated to reflux at $200{ }^{\circ} \mathrm{C}$. The reaction mixture was maintained at the aforementioned temperature for $48 \mathrm{~h}$ with constant magnetic stirring. It was then allowed to cool down to room temperature and the polymer was obtained by vacuum filtration and washed with water $(3 \times 200 \mathrm{~mL})$ and acetone $(3 \times 100 \mathrm{~mL})$ several times to remove any unreacted $\mathrm{Na}_{2} \mathrm{~S}$ and dichloroanthraquinone (DCAQ). The filtered polymer was then dried at $60{ }^{\circ} \mathrm{C}$ under vacuum for $12 \mathrm{~h}$ after which dark brown colored powders were obtained. The yield was about 81\% (3.5 g) for 1,5-PAQS, 70\% (3.0 g) for 1,8-PAQS and 89\% (3.8 g) for 1,8-PAQS.

${ }^{1} \mathrm{H}$ liquid NMR spectra were recorded at $300 \mathrm{MHz}$ on a Bruker Avance 300 spectrometer, and elemental analysis of $\mathrm{C}$, $\mathrm{H}, \mathrm{N}, \mathrm{O}, \mathrm{S}$ and $\mathrm{Cl}$ was conducted by the "Institut des Sciences Analytiques" (ISA, UMR CNRS 5280, Lyon, France) on various equipment. $^{39}$ XRD spectra were recorded at the "Institut de Recherche de Chimie Paris" (IRCP, UMR CNRS 8247, Paris, France) on a D8 Endeavor X-ray diffractometer (Bruker) equipped with a $\mathrm{Cu}$ source $\left(\mathrm{K}_{\alpha}, \lambda=1.54 \AA\right)$. Raman spectra were recorded on a Horiba HR Evolution $(532 \mathrm{~nm})$ at $5 \%$ of the maximum power. Thermogravimetric analysis (TGA) was performed on a STA 6000 (PerkinElmer) within the temperature range of $30-700{ }^{\circ} \mathrm{C}$ at a heating rate of $5{ }^{\circ} \mathrm{C} \min ^{-1}$ under a $\mathrm{N}_{2}$ atmosphere.

\section{Cell preparation and electrochemical measurements}

Electrode preparation ( $40 \%$ polymer, $50 \%$ conductive carbon, $\mathbf{1 0 \%}$ binder). An appropriate amount of dry polymer powder was manually milled in an agate mortar with Ketjen Black carbon for $30 \mathrm{~min}$. The mixed powder obtained was transferred to a vial with a big stirrer, then a $5 \mathrm{wt} \%$ solution of $\mathrm{PVdF}$ (Kynar ${ }^{\circledR}$ HSV 990, Arkema) binder dissolved in $N$-methyl-2pyrrolidone (NMP, Sigma Aldrich) was added. In order to obtain a slurry texture, additional pure NMP was introduced until the desired density was reached and the mixture was stirred at room temperature for $2 \mathrm{~h}$. The resulting dense slurry was painted with a fine brush on conductive carbon paper (GDL $28 \mathrm{BC}$, SGL Group) previously punched at $14 \mathrm{~mm}$ diameter. These "wet" electrodes were then dried overnight in a $50{ }^{\circ} \mathrm{C}$ oven to remove the maximum amount of NMP, and then transferred into a glass oven (BÜCHI B-585) and heated again at $50{ }^{\circ} \mathrm{C}$ under reduced pressure for $4 \mathrm{~h}$. Finally, the electrodes were measured on a Sartorius MSA 66.5-000-DM balance with $\pm 0.001 \mathrm{mg}$ accuracy (a typical electrode had an active material loading of about $1 \mathrm{mg}$ ) and were then stored in a glove box. In a CR2032 type coin cell (Hohsen Corp.), a piece of lithium ribbon (thickness $0.75 \mathrm{~mm}, 99.9 \%$, Sigma Aldrich) was used as the counter electrode and separated from the PAQS electrode by two sheets of GF/C type Whatman ${ }^{\circledR}$ glass microfiber filters punched at $16 \mathrm{~mm}$ diameters and soaked with $200 \mu \mathrm{L}$ of electrolyte consisting of $1 \mathrm{M}$ lithium bis(trifluoromethanesulfonyl) imide (LiTFSI, 99\%, Fluorochem) dissolved in a 1,3-dioxolane/ 1,2-dimethoxyethane (1:1 v/v) mixture (both 99.5\%, Sigma-Aldrich). 

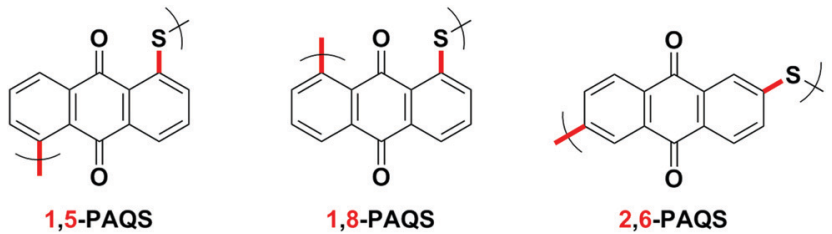

Fig. 1 The chemical structure of 1,5-PAQS, 1,8-PAQS and 2,6-PAQS

Table 1 Elemental analysis results of poly-anthraquinone sulfide isomers and evaluation of their degree of polymerization

\begin{tabular}{lllllll}
\hline & $\begin{array}{l}\text { Carbon } \\
(\%)\end{array}$ & $\begin{array}{l}\text { Hydrogen } \\
(\%)\end{array}$ & $\begin{array}{l}\text { Oxygen } \\
(\%)\end{array}$ & $\begin{array}{l}\text { Sulfur } \\
(\%)\end{array}$ & $\begin{array}{l}\text { Chlorine } \\
(\%)\end{array}$ & $\mathrm{DP}_{n}$ \\
\hline Theoretical & 70.57 & 2.54 & 13.43 & 13.46 & 0 & - \\
1,5-PAQS & 61.48 & 2.48 & 12.17 & 10.92 & 2.10 & 12 \\
1,8-PAQS & 66.51 & 2.80 & 12.51 & 13.35 & 3.63 & 8 \\
2,6-PAQS & 65.13 & 2.72 & 12.34 & 9.84 & 0.67 & 41
\end{tabular}

The entire cell assembly process was performed inside a glove box in which the moisture and oxygen levels were below $5 \mathrm{ppm}$. Coin cells were placed in CR2032 coin cell holders (Origalys Electrochem) and electrochemical characterization was performed with a Biologic BCS-805 battery cycler and/or a Biologic VMP-3. For low temperature measurements, channel cables were entered in a dynamic climate chamber (Binder MK056) through a dedicated access and subsequently isolated by glass wool. The climate chamber was set at the targeted temperature $\left( \pm 0.1{ }^{\circ} \mathrm{C}\right)$ and a stabilization time of $2 \mathrm{~h}$ was applied before running each experiment in order to ensure that all the systems (coin cell, electrolyte, etc.) reached the operating temperature. For cycling at $60{ }^{\circ} \mathrm{C}$, the same procedure was employed in an oven (Memmert UN30). $225 \mathrm{~mA} \mathrm{~h} \mathrm{~g}^{-1}$ was assumed as the theoretical capacity for calculating currents. The cutoff voltages of the cyclic voltammetry and galvanostatic cycling tests were 1.5-3.2 V. Coupled galvanostatic-EIS tests were performed on CR-2032 half-cells, with a voltage amplitude of $10 \mathrm{mV}$ and a frequency range of $1 \mathrm{MHz}$ to $1 \mathrm{mHz}$.

\section{Results and discussion}

1,5-PAQS, 1,8-PAQS and 2,6-PAQS (Fig. 1) were easily prepared by refluxing a solution of corresponding dichloroanthraquinone (DCAQ) with anhydrous sodium sulfide $\left(\mathrm{Na}_{2} \mathrm{~S}\right)$ in $\mathrm{N}$-methyl 2-pyrrolidone (NMP) at $200{ }^{\circ} \mathrm{C}$ according to methods described previously ${ }^{6,16,28}$ (Scheme 2). The reaction mixture was kept at the aforementioned temperature for $48 \mathrm{~h}$ with constant magnetic stirring. The purified 1,5-PAQS, 1,8-PAQS and 2,6-PAQS were isolated with a yield of $81 \%, 70 \%$ and $89 \%$, respectively. The chemical structures of 1,5-PAQS, 1,8-PAQS and 2,6-PAQS obtained were checked by elemental analysis and polymerization degrees $\left(\mathrm{DP}_{n}\right)$ were deduced from the data.

Table 1 summarizes the data from elemental analysis and the evaluation of the degree of polymerization which is extracted from it as described by Wang et al. ${ }^{26}$ As an example, the reduction of $\mathrm{Cl} \%$ from 25.59 in 2,6-DCAQ to 0.67 in 2,6-PAQS indicates that almost all of the $\mathrm{Cl}$ atoms were eliminated during the polymerization reaction. In this case the final $\mathrm{C} / \mathrm{Cl}$ molar ratio is equal to 287 and the initial is 7 . All the terminal groups of the polymer are assumed to be $\mathrm{Cl}$ atoms, as a consequence, the polymerization degree is about $287 / 7, \mathrm{DP}_{n}=41$.

The materials obtained were characterized by XRD and Raman spectroscopy (Fig. 2) and subjected to thermogravimetric analysis (Fig. S2, ESI $\dagger$ ). XRD for the studied PAQS isomers shows low crystallinity to amorphous patterns depending on the isomer (Fig. 2a), which is common for polyquinones and consistent with the literature data for 1,5-PAQS. ${ }^{40}$ For 2,6-PAQS, peaks were less well-defined but still in the same $2 \theta$ angles, while 1,8-PAQS displayed only a very broad region without any defined peaks.

The formation of $\mathrm{C}-\mathrm{S}$ bonds was investigated by Raman spectroscopy and they were found to appear between 650 and $750 \mathrm{~cm}^{-1}$ (highlighted band) which is consistent with the range of the $\mathrm{C}-\mathrm{S}$ bond stretching vibrations. ${ }^{41,42}$ As depicted in Fig. 2b, only a small peak can be observed for 1,8-PAQS,

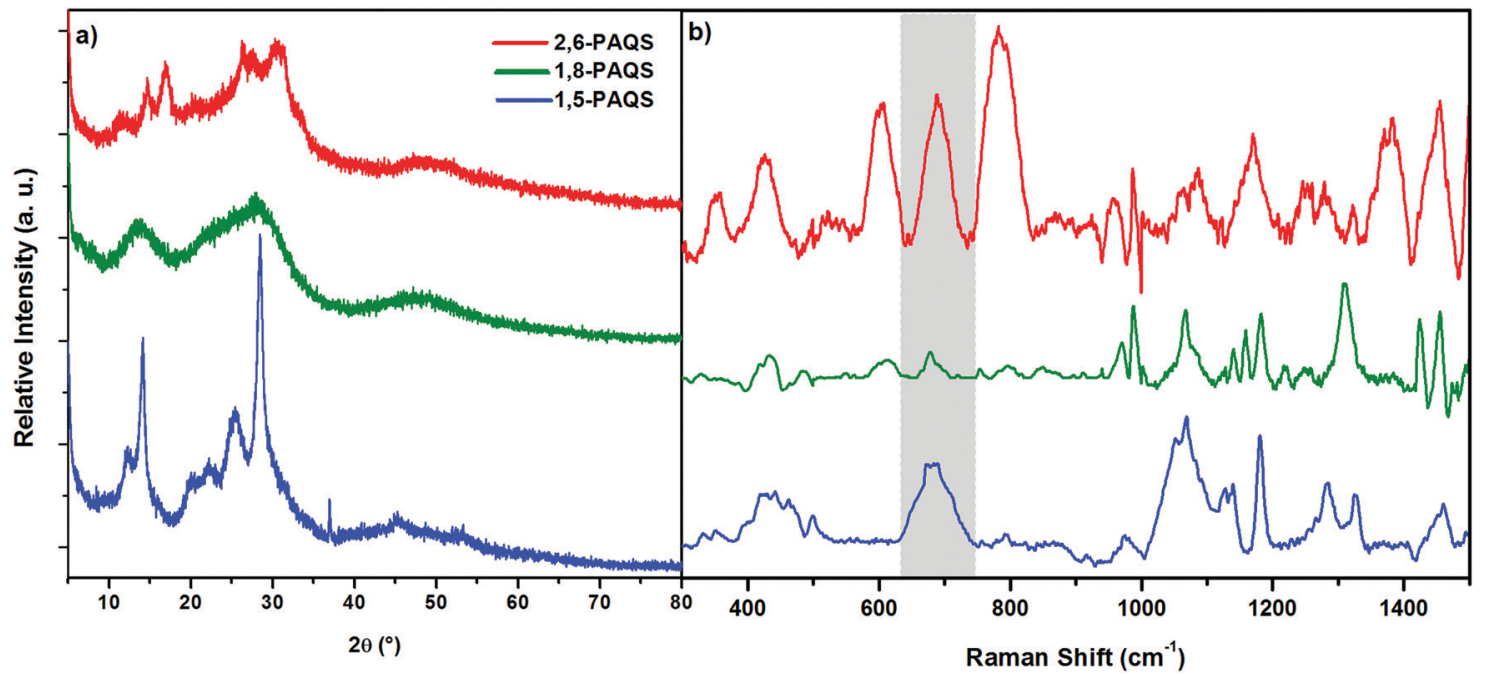

Fig. 2 (a) XRD patterns of the synthesized PAQS isomers and (b) Raman spectra of PAQS isomer powders. 

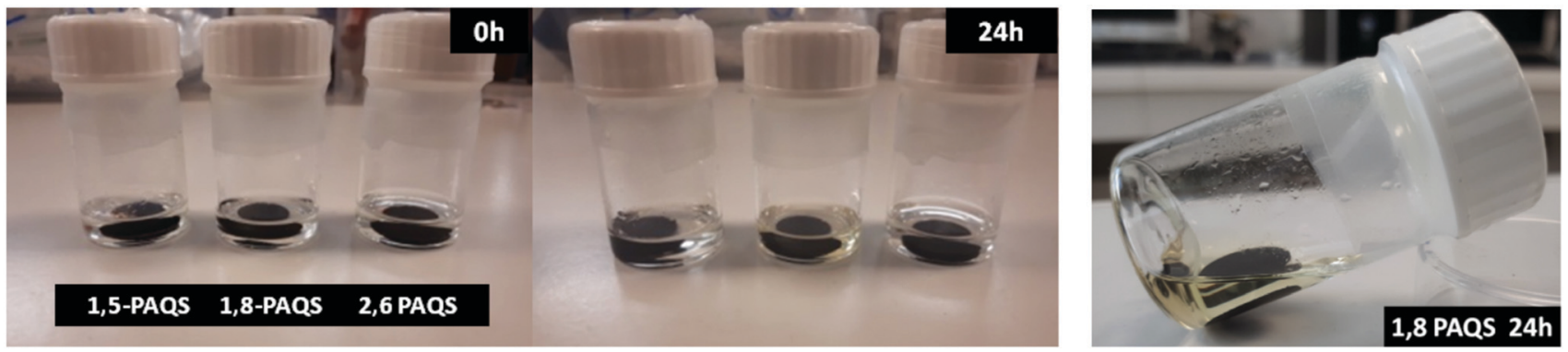

Fig. 3 Pictures showing the dissolution behavior of PAQS electrode materials in $1 \mathrm{M}$ LiTFSI DOL/DME $(1: 1 \mathrm{v} / \mathrm{v})$.

whereas a band can be seen for 1,5-PAQS and an intense one for 2,6-PAQS. These different intensities are correlated with the related degree of polymerization $\left(\mathrm{DP}_{n}\right)$ : the lower the $\mathrm{DP}_{n}$, the weaker the intensity of the C-S band (Table 1).

TGA analysis (Fig. S2, ESI $\dagger$ ) for PAQS showed no variations up to $270{ }^{\circ} \mathrm{C}$ for 2,6-PAQS and $360{ }^{\circ} \mathrm{C}$ for 1,5-PAQS. The 1,8-PAQS curve seems to show a loss of water equal to $15 \%$ of the total mass which may correspond to residual water trapped in the polymer. The second weight loss appeared after $330{ }^{\circ} \mathrm{C}$ and corresponds to thermal degradation of 1,8-PAQS.

The main drawback of quinone as a monomer or oligomers is their solubility in organic solvents that are commonly used in lithium-ion batteries. As shown by visual solubility tests in Fig. 3, only the vial containing the 1,8-PAQS electrode exhibited a pale-yellow color after $24 \mathrm{~h}$. This coloration did not evolve over a week, and the other two were still uncolored after seven days
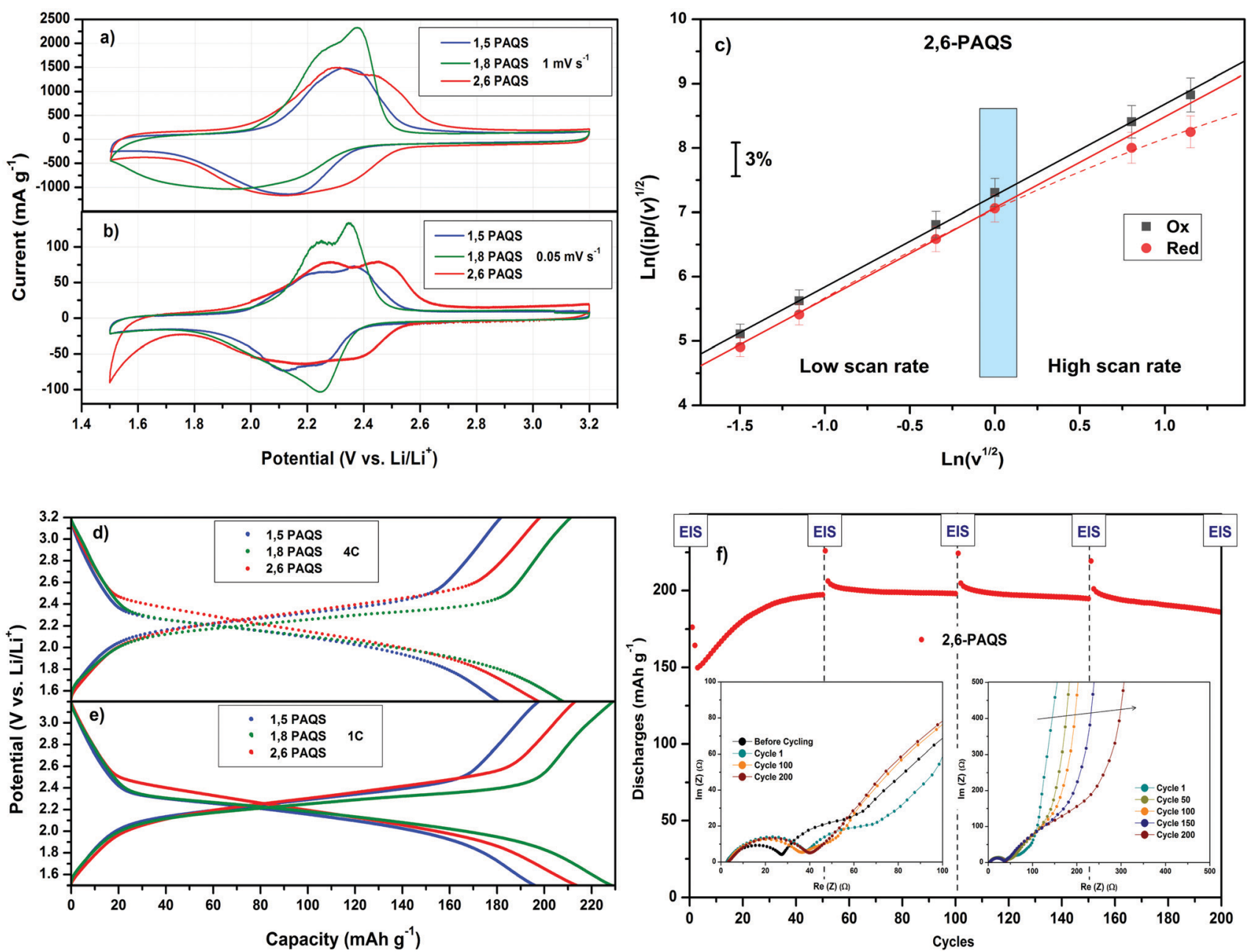

Fig. 4 (a) and (b) Cyclic voltammetry of PAQS isomers with $1 \mathrm{M}$ LiTFSI in DOL/DME at 1.00 and $0.05 \mathrm{mV} \mathrm{s}^{-1}$. (c) Evolution of normalized current (ip) as a function of the square root of the scan rate $v$. (d) and (e) Galvanostatic profiles of each PAQS isomer at 4C and 1C. (f) 2,6-PAQS impedance evolution during galvanostatic cycling at $4 \mathrm{C}$. 
Table 2 Performance comparison of our 2,6-PAQS with examples from the literature

\begin{tabular}{|c|c|c|c|}
\hline & \multicolumn{3}{|c|}{ Capacity retention/cycles/current } \\
\hline & $219 \mathrm{~mA} \mathrm{~h} \mathrm{~g} / 1 \mathrm{C}$ & $52 \% / 100 / 1 \mathrm{C}$ & 45 \\
\hline & $137 \mathrm{~mA} \mathrm{~h} \mathrm{~g}^{-1} / 1 \mathrm{C}$ & $86 \% / 100 / 5 \mathrm{C}$ & 46 \\
\hline & $214 \mathrm{~mA} \mathrm{~h} \mathrm{~g}^{-1} / 50 \mathrm{~mA} \mathrm{~g}^{-1}$ & $47 \% / 20 / 50 \mathrm{~mA} \mathrm{~g}^{-1}$ & 15 \\
\hline & $275 \mathrm{~mA} \mathrm{~h} \mathrm{~g}{ }^{-1} / 50 \mathrm{~mA} \mathrm{~g}^{-1}$ & $86 \% / 1000 / 500 \mathrm{~mA} \mathrm{~g}^{-1}$ & 47 \\
\hline & $200 \mathrm{~mA} \mathrm{~h} \mathrm{~g}^{-1} / 4 \mathrm{C}$ & $94 \% / 1000 / 4 \mathrm{C}\left(800 \mathrm{~mA} \mathrm{~g}^{-1}\right)$ & This work \\
\hline
\end{tabular}

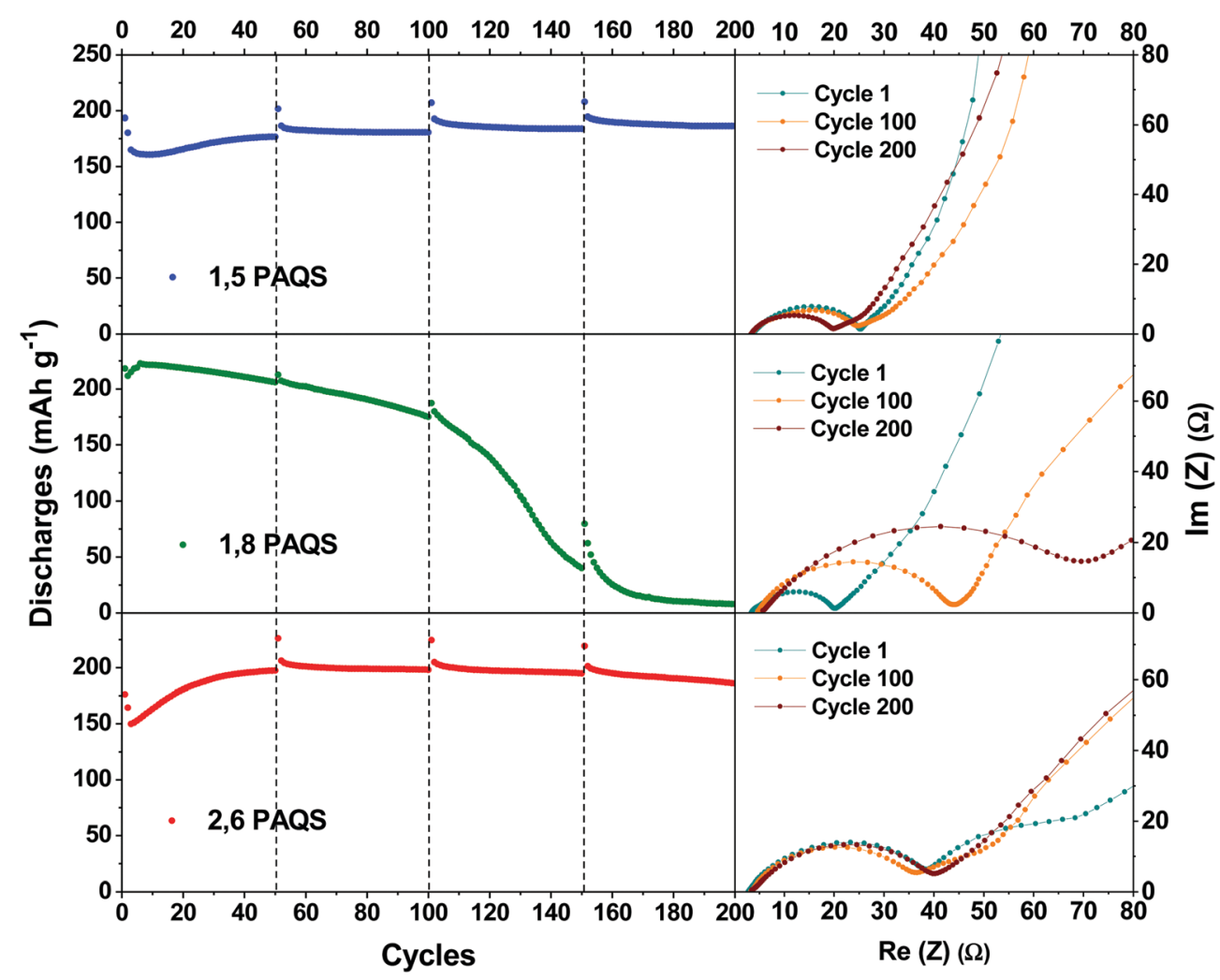

Fig. 5 Nyquist plots of a Li-PAQS coin cell after the 1st, 100th, and 200th cycle under a current rate of $4 \mathrm{C}$ and the corresponding evolution of discharge capacities.

(Fig. S3, ESI $\dagger$ ). 2,6-PAQS, thanks to its high polymerization degree, was not soluble in our electrolyte. As revealed by the pictures, 1,8PAQS can be dissolved by the electrolyte; this was no doubt caused by its low degree of polymerization. Lastly, despite a very similar polymerization degree to that of 1,8-PAQS, 1,5-PAQS was not soluble in the $1 \mathrm{M}$ LiTFSI DOL/DME mixture. 
Fig. $4 \mathrm{a}$ and $\mathrm{b}$ shows the comparative cyclic voltammograms (CV) for the three PAQS isomers at two scan rates $v\left(\mathrm{mV} \mathrm{s}^{-1}\right)$ with $1 \mathrm{M}$ LiTFSI in 1,3-dioxolane/dimethoxyethane (DOL/DME: $1 / 1, \mathrm{v} / \mathrm{v}$ ) as electrolyte. At a low scan rate $v=0.05 \mathrm{mV} \mathrm{s}^{-1}$, the two-step bielectronic redox mechanism for the reversible electrochemical reaction between lithium ions and carbonyl groups in the conjugated organic framework is visible and appear as a pair of peaks centered in the oxidation step at $2.3 \mathrm{~V}$ for 1,5-PAQS and 1,8-PAQS and $2.35 \mathrm{~V}$ for 2,6-PAQS. In the reduction step, a broad peak is observed at $2.25 \mathrm{~V} \mathrm{vs.} \mathrm{Li}^{+} / \mathrm{Li}$. In all cases, the potential hysteresis is downsized to $0.10 \mathrm{~V}$, indicating a low polarization during the redox process at this slow scan rate. At $1 \mathrm{mV} \mathrm{s}^{-1}$, the peaks are less clearly separated and the observed dissymmetry is attributed to the different diffusion rates into electrode materials between the oxidation and reduction steps. For 2,6-PAQS, electrochemical reversibility (electron transfer $/ \mathrm{Li}^{+}$compensation) of the concerted process was checked (Fig. 4c) by the analysis of $\mathrm{Ip}^{\mathrm{c}}$ and $\mathrm{Ip}^{\mathrm{a}}$ as a function of the square root of the scan rate, $v^{1 / 2}$ for linearity. ${ }^{43}$

For both oxidation and reduction, the investigated systems show the expected behavior for a diffusion limited process. This can be explained by a fast electron transfer and $\mathrm{Li}^{+}$charge compensation, which does not influence the electrode response substantially. ${ }^{44}$ At a high scan rate $v>1 \mathrm{mV} \mathrm{s}^{-1}$, ip ${ }^{\mathrm{c}}$ showed a slight deviation from linearity, which means that at this rate, the approach of the $\mathrm{Li}^{+}$cation to compensate the charge is the limiting step.

Fig. 4d and e present the galvanostatic profiles of each PAQS isomer at two different C-rates. These profiles show very high capacities at $1 \mathrm{C}$ for each isomer, starting from $192 \mathrm{~mA} \mathrm{~h} \mathrm{~g}^{-1}$ for 1,5-PAQS, $212 \mathrm{~mA} \mathrm{~h} \mathrm{~g}^{-1}$ for 2,6-PAQS and ending at $224 \mathrm{~mA} \mathrm{~h} \mathrm{~g}^{-1}$ for 1,8-PAQS. At a faster C-rate (4C), the same ranking is found, with only slight decreases in capacities (only 10 to $15 \mathrm{~mA} \mathrm{~h} \mathrm{~g}^{-1}$ ). These capacities at a fast C-rate are higher than most conventional anodes and cathodes, such as LTO, LFP or LCO and also a competitive alternative of other related organic redox materials (Table 2).

As mentioned above, the capacities are in the following order: 1,8-PAQS > 2,6-PAQS > 1,5-PAQS. Unlike with a low C-rate $(1 \mathrm{C})$, with a faster cycling $(4 \mathrm{C})$ the half charge hysteresis is inverted and the order is changed as follows: 2,6-PAQS < 1,5-PAQS $<$ 1,8-PAQS which is consistent with the previous observation for cyclic voltammetry. PAQS isomers seem to be sensitive to the C-rate, depending on the mechanical rigidity of the polymer backbone and its degree of polymerization. This hypothesis is corroborated by Fig. 4f and 5. During galvanostatic cycling at 4C, 2,6-PAQS shows progressive adaptation by gradual increases of its initial capacities due to the shaping of the polymer resulting from the repetitive redox processes. During the galvanostatic sequence, impedance measurements showed that the Warburg increases only for 2,6-PAQS, which indicates a slower diffusion in the material and consequently a greater resistance. These results confirm the effect of the isomerism on the polymer chain on the electrochemical response and consequently on the stability of PAQS during cycling. Thus 1,8-PAQS, which is more rigid, seems disfavored for a prolonged reversible redox process by comparison of the two other isomers, independently to their polymerization degree.

Fig. 6a compares the rate capability for PAQS isomers at a current rate (from $\mathrm{C} / 5$ to 50C). PAQS delivers a reversible capacity above $220 \mathrm{~mA} \mathrm{~h} \mathrm{~g}{ }^{-1}$ at $\mathrm{C} / 5$ for all isomers corresponding to the quasi-theoretical capacity, and it still delivers $120 \mathrm{~mA} \mathrm{~h} \mathrm{~g}{ }^{-1}\left(0.6 \mathrm{~A} \mathrm{~g}^{-1}\right)$ and $60 \mathrm{~mA} \mathrm{~h} \mathrm{~g}{ }^{-1}\left(0.3 \mathrm{~A} \mathrm{~g}^{-1}\right)$ for 2,6-PAQS and 1,5-PAQS respectively at 50C. In contrast, 1,8-PAQS does not support high current density and the capacity collapses for C-rates above $5 \mathrm{C}$.

Performances during long-term cycling up to 1000 cycles (Fig. 6b and c) show that 1,8-PAQS still suffers from fast cycling (4C) as its discharge capacities do not stabilize but fade continuously and end up collapsing after 200 cycles. In contrast, 1,5-PAQS and 2,6-PAQS, after stabilization, can be cycled over a thousand times with capacities close to $200 \mathrm{~mA} \mathrm{~h} \mathrm{~g}{ }^{-1}$ (88\% of the theoretical PAQS capacity). At the end of the 1000 cycles, the capacity retention is over $94-97 \%$ of the initial capacity for 2,6-PAQS and 1,5-PAQS, respectively.

The good performances of 1,5-PAQS demonstrate the secondary role of the polymerization degree $\left(\mathrm{DP}_{n}=12\right)$ in achieving
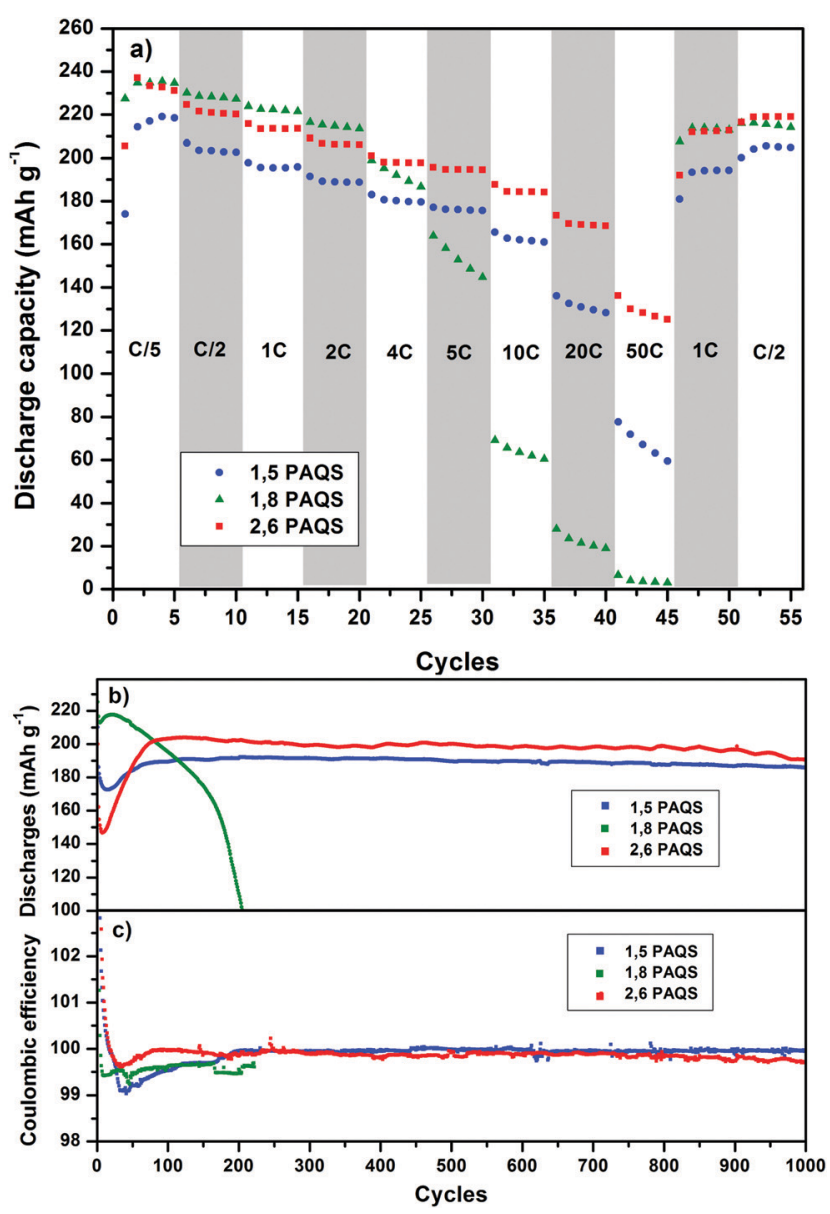

Fig. 6 (a) Rate capability at room temperature for each PAQS isomer at a current rate from $\mathrm{C} / 5$ to $50 \mathrm{C}$. (b) Long-term cycling profiles of PAQS isomers at $4 \mathrm{C}$ and (c) their corresponding coulombic efficiencies. 


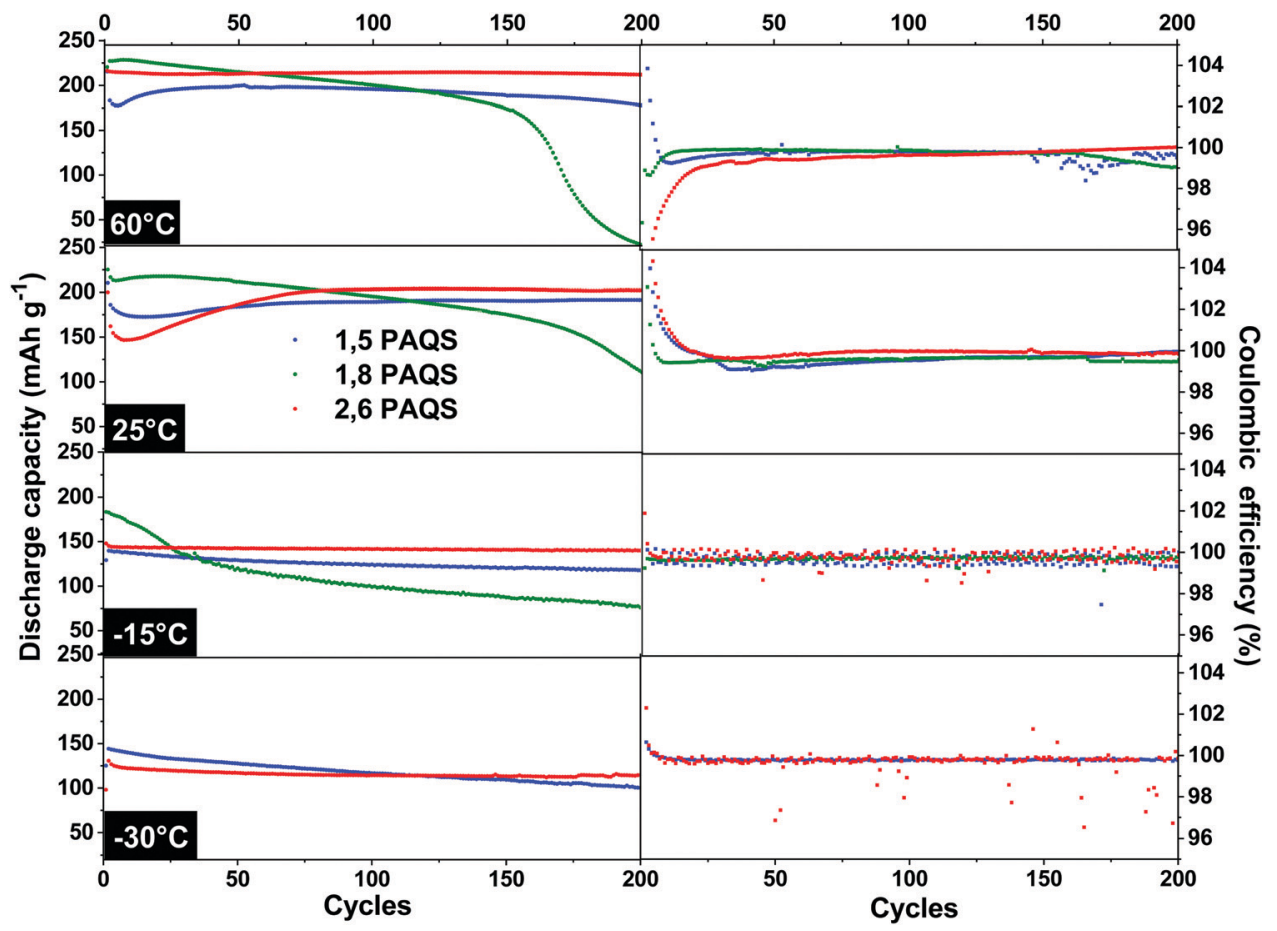

Fig. 7 Discharge capacities and corresponding coulombic efficiencies of PAQS isomers from $60{ }^{\circ} \mathrm{C}$ to $-30{ }^{\circ} \mathrm{C}$ at $4 \mathrm{C}$.

long-term cycling, in contradiction with what has been previously described. ${ }^{26}$ By presenting at the same time a high polymerization degree, the best capacities, and a rate capability at very high current density, 2,6-PAQS seems to be the most promising PAQS isomer for an organic battery electrode.

The temperature effect on stability during cycling was evaluated by galvanostatic cycling (4C) over 200 cycles at temperatures ranging from $60{ }^{\circ} \mathrm{C}$ to $-30{ }^{\circ} \mathrm{C}$ for all PAQS isomers. The results are presented in Fig. 7.

The 1,8-PAQS discharge capacities were even more unstable at $60{ }^{\circ} \mathrm{C}$ than at $25{ }^{\circ} \mathrm{C}$, with faster fading. At $-15{ }^{\circ} \mathrm{C}$ even if the starting capacities were better $\left(185 \mathrm{~mA} \mathrm{~h} \mathrm{~g}^{-1}\right)$ and the capacity fading more contained, performances still did not match the stability requirements. Lastly, unlike the other two isomers, 1,8-PAQS was not able to cycle at $-30^{\circ} \mathrm{C}$. At $60^{\circ} \mathrm{C}, 2,6-\mathrm{PAQS}$ exhibited a better capacity and stability $\left(211 \mathrm{~mA} \mathrm{~h} \mathrm{~g}^{-1}, 200\right.$ th cycle) than 1,5-PAQS with a capacity retention of $98.1 \% v s$. $89.4 \%$ for 2,6-PAQS and 1,5-PAQS respectively, associated with the excellent coulombic efficiencies for both. At low temperatures, $-15{ }^{\circ} \mathrm{C}$ and $-30{ }^{\circ} \mathrm{C}$, the capacity of the two PAQS showed an expected decrease due to the slowdown in electron transfers and diffusion. For 2,6-PAQS, a capacity retention of $95.2 \%$ was observed with $138 \mathrm{~mA} \mathrm{~h} \mathrm{~g}^{-1}$ after the 200th cycle at $-15^{\circ} \mathrm{C}$, and $120 \mathrm{~mA} \mathrm{~h} \mathrm{~g}{ }^{-1}$ after the 200 th cycle at $-30{ }^{\circ} \mathrm{C}$. The 1,5-PAQS isomer exhibited comparable but slightly weaker results. It is clear that the 2,6-PAQS isomer adapts better to temperature variation and provides a better performance. At $-30{ }^{\circ} \mathrm{C}$, 2,6-PAQS delivered a remarkable discharge energy density, $E_{\mathrm{D}}$, of $275 \mathrm{~W} \mathrm{~h} \mathrm{~kg}^{-1}\left(E_{\mathrm{D}}=U_{\mathrm{D}} \cdot C\right.$; with $C=120 \mathrm{~mA} \mathrm{~h} \mathrm{~g}^{-1}$ and $U_{\mathrm{D}}=2,29 \mathrm{~V} v s . \mathrm{Li}^{+} / \mathrm{Li}$ ) without any adaptation of the baseline electrolyte to low temperature operations.

\section{Conclusions}

In summary, three PAQS isomers were synthesized, and characterized in a comparative study of their electrochemical performances as organic electrode materials. Slightly higher charging and discharging voltages were observed during cyclic voltammetry and are clearly due to the C-S position of the isomer. The galvanostatic tests showed that only the 1,5 and the 2,6-PAQS isomers were able to tolerate rates higher than 4C and long-term cycling (1000 cycles). In addition, the 2,6-PAQS isomer demonstrated a remarkable ability to endure fast cycling from $60{ }^{\circ} \mathrm{C}$ to $-30{ }^{\circ} \mathrm{C}$ without a significant decrease in capacity retention (which decreased from $98.1 \%$ to $93.4 \%$ ) thanks to its flexible structure. These results allow 2,6-PAQS to deliver an energy density of $275 \mathrm{~W} \mathrm{~h} \mathrm{~kg}^{-1}$ at $-30{ }^{\circ} \mathrm{C}$. It therefore appears to be a promising candidate as an alternative cathode for primary batteries with extended operating temperatures as well as a negative electrode in full-organic batteries dedicated to low temperature operation.

\section{Conflicts of interest}

The authors declare no competing financial interest.

\section{Acknowledgements}

The authors would like to thank "La Région Centre Val de Loire" for financial support through the Obama project under the Lavoisier II regional program. 


\section{References}

1 J. M. Tarascon and M. Armand, Nature, 2001, 414, 359-367. 2 D. Larcher and J. M. Tarascon, Nat. Chem., 2015, 7, 19-29.

3 C. P. Grey and J. M. Tarascon, Nat. Mater., 2017, 16, 45-56.

4 A. Mauger, C. Julien, A. Paolella, M. Armand and K. Zaghib, Materials, 2019, 12, 1-86.

5 J. Xu, H. R. Thomas, R. W. Francis, K. R. Lum, J. Wang and B. Liang, J. Power Sources, 2008, 177, 512-527.

6 S. Muench, A. Wild, C. Friebe, B. Häupler, T. Janoschka and U. S. Schubert, Chem. Rev., 2016, 116, 9438-9484.

7 H. Nishide and K. Oyaizu, Science, 2008, 319, 737-738.

8 M. Armand and J. M. Tarascon, Nature, 2008, 451, 652-657.

9 H. Chen, M. Armand, M. Courty, M. Jiang, C. P. Grey, F. Dolhem, J.-M. Tarascon and P. Poizot, J. Am. Chem. Soc., 2009, 131, 8984-8988.

10 Y. Liang, Z. Tao and J. Chen, Adv. Energy Mater., 2012, 2, 702. 11 Z. Song and H. Zhou, Energy Environ. Sci., 2013, 6, 2280-2301. 12 W. Huang, Z. Zhu, L. Wang, S. Wang, H. Li, Z. Tao, J. Shi, L. Guan and J. Chen, Angew. Chem., Int. Ed., 2013, 52, 9162-9166.

13 Z. Song, Y. Qian, X. Liu, T. Zhang, Y. Zhu, H. Yu, M. Otani and H. Zhou, Energy Environ. Sci., 2014, 7, 4077-4086.

14 S. Wang, L. Wang, Z. Zhu, Z. Hu, Q. Zhao and J. Chen, Angew. Chem., Int. Ed., 2014, 53, 5892-5896.

15 L. Zhao, J. Zhao, Y.-S. Hu, H. Li, Z. Zhou, M. Armand and L. Chen, Adv. Energy Mater., 2012, 2, 962-965.

16 Y. Chen, W. Luo, M. Carter, L. Zhou, J. Dai, K. Fu, S. Lacey, T. Li, J. Wan, X. Han, Y. Bao and L. Hu, Nano Energy, 2015, 18, 205-211.

17 Z. Jian, Y. Liang, I. A. Rodríguez-Pérez, Y. Yao and X. Ji, Electrochem. Commun., 2016, 71, 5-8.

18 T. B. Schon, B. T. McAllister, P.-F. Li and D. S. Seferos, Chem. Soc. Rev., 2016, 45, 6345-6404.

19 G. A. Snook, P. Kao and A. S. Best, J. Power Sources, 2011, 196, 1-12.

20 W. Choi, D. Harada, K. Oyaizu and H. Nishide, J. Am. Chem. Soc., 2011, 133, 19839-19843.

21 J. Cao and A. Emadi, IEEE Trans. Power Syst., 2012, 27, 122-132.

22 L. Kouchachvili, W. Yaïci and E. Entchev, J. Power Sources, 2018, 374, 237-248.

23 R. Thangavel, K. Kaliyappan, D.-U. Kim, X. Sun and Y.-S. Lee, Chem. Mater., 2017, 29, 7122-7130.

24 K. Oka, S. Furukawa, S. Murao, T. Oka, H. Nishide and K. Oyaizu, Chem. Commun., 2020, 56, 4055-4058.

25 C. Han, H. Li, R. Shi, T. Zhang, J. Tong, J. Li and B. Li, J. Mater. Chem. A, 2019, 7, 23378-23415.
26 Z. Song, Y. Qian, M. L. Gordin, D. Tang, T. Xu, M. Otani, H. Zhan, H. Zhou and D. Wang, Angew. Chem., Int. Ed., 2015, 54, 13947-13951.

27 Z. Song, H. Zhan and Y. Zhou, Chem. Commun., 2009, 448-450.

28 S. Phadke, M. Cao and M. Anouti, ChemSusChem, 2018, 11, 965-974.

29 J. Tong, C. Han, X. Hao, X. Qin and B. Li, ACS Appl. Mater. Interfaces, 2020, 12, 39630-39638.

30 Y. Lu, X. Hou, L. Miao, L. Li, R. Shi, L. Liu and J. Chen, Angew. Chem., Int. Ed., 2019, 58, 7020-7024.

31 Y. Zou, V. Raveendran and J. Chen, Nano Energy, 2020, 77, 105303.

32 C. Liu, T. Ma, K. Xia, X. Hou, Q. Nian, Y. Cai and J. Liang, Sustainable Energy Fuels, 2020, 4, 132-137.

33 Z. Man, P. Li, D. Zhou, R. Zang, S. Wang, P. Li, S. Liu, X. Li, Y. Wu, X. Liang and G. Wang, J. Mater. Chem. A, 2019, 7, 2368-2375.

34 W. Deng, X. Liang, X. Wu, J. Qian, Y. Cao, X. Ai, J. Feng and H. Yang, Sci. Rep., 2013, 3, 2671.

35 T. Kawai, K. Oyaizu and H. Nishide, Macromolecules, 2015, 48, 2429-2434.

36 J. T. Edmonds and H. W. Hill, Production of polymers from aromatic compounds, US Pat., US3354129A, 1967.

37 Y. Zhang, I. Murtaza, D. Liu, R. Tan, Y. Zhu and H. Meng, Electrochim. Acta, 2017, 224, 622-627.

38 K. W. Bair, Anthracene derivatives, US Pat., US4719049A, 1988.

39 https://isa-lyon.fr/?page_id=2908.

40 A. Ahmad, A. Imani, L. Mao, R. Iqbal, H. Zhang, Z. A. Ghazi, R. Ahmad, A. A. Khan, L. Xie, C.-M. Chen, Z. Zhang and Z. Wei, Adv. Mater. Technol., 2019, 4, 1900617.

41 D. Lin-Vien, N. B. Colthup, W. G. Fateley and J. G. Grasselli, The Handbook of Infrared and Raman Characteristic Frequencies of Organic Molecules, 1991, pp. 225-250, ch. 14.

42 J. H. S. Green, Spectrochim. Acta, 1962, 18, 39-50.

43 N. Parveen and R. Kant, J. Phys. Chem. C, 2014, 118, 26599-26612.

44 S. A. Petrova, M. V. Kolodyazhny and O. S. Ksenzhek, J. Electroanal. Chem. Interfacial Electrochem., 1990, 277, 189-196.

45 J. Kim, J. Kim, J. Lee, H.-K. Song and C. Yang, ChemElectroChem, 2014, 1, 1618-1622.

46 B. Häupler, T. Hagemann, C. Friebe, A. Wild and U. S. Schubert, ACS Appl. Mater. Interfaces, 2015, 7, 3473-3479.

47 Z. Song, Y. Qian, T. Zhang, M. Otani and H. Zhou, Adv. Sci., 2015, 2, 1500124. 